\title{
OPEN Assessing effectiveness of exclusion fences in protecting threatened plants
}

\author{
Juan Lorite ${ }^{1,2 \bowtie}$, Carlos Salazar-Mendías ${ }^{3}$, Roza Pawlak $^{1} \&$ Eva María Cañadas ${ }^{1}$
}

Overgrazing stands out as threat factors on biodiversity, being especially harmful in the Mediterranean, due to strong human pressure and an accelerated climate change acting synergistically. Fencing is a common tool used in conservation biology to tackle this problem. Advantages of fences are usually fast, intuitive, and easy to evaluate. However, disadvantages could also arise (increasing interspecific competition, disturbing habitat structure, limiting pollination, reducing dispersion). Together with management issues (maintenance, conflicts with stakeholders, and pulling effect). Effectiveness of fencing for conservation has been frequently assessed for animals, while it is almost a neglected topic in plants. We evaluated the outcome of fencing three threatened and narrow-endemic plants. Selected 5 populations were only partly fenced, which allowed comparing different variables inside and outside the fence. For evaluating the fencing effects, we sampled several habitats (vegetation cover, composition, density of target species), and target-species features (individual size, neighbouring species, and fruit-set). Fencing had strong effects on the habitat and on target-species individuals, showing contrasting responses at species and population level. Particularly, for Erodium cazorlanum, fence had a positive effect in one case, and negative in another. In Hormathophylla baetica effect was positive in all populations. Finally, fencing negatively affected Solenanthus reverchonii by increasing competition and limiting seed-dispersal. Fencing outcome was different in assessed species, highlighting the need to a case-by-case evaluation to determine the net balance (pros vs. cons), also its suitability and most favourable option (i.e. permanent vs. temporary fences).

Land-use activities have transformed a large proportion of the planet's land surface becoming an important driver of the ongoing global change ${ }^{1}$. Within the land-use activities overgrazing, both wild- and domesticanimals caused, is among the most detrimental ones. In fact, it has strong links with erosion, biodiversity loss and desertification in large areas worldwide ${ }^{1,2}$. Nowadays, overgrazing is an important threatening factor for plant species, especially for endemic ones due to their restricted distribution area, usually encompasses with low population sizes ${ }^{3}$. Despite this general pattern, some endemic and/or threatened species could be favoured by a high grazing pressure, or even overgrazing that limit interspecific competition ${ }^{4}$, or creating a window of opportunity for some species (i.e. annual species) . $^{5}$

One of the most used tools since the Neolithic Age to protect plants (usually crops) from the herbivores is fencing ${ }^{6}$. In conservation biology fencing is one tool of the conservation managers' arsenal that can separate threats from biodiversity. Fencing is referred not only to physical barriers, such as a standard post and wire fence, but also metaphorical ones, such as inhospitable land, gardens of chilli, walls of noise, effective anti-poaching patrols or buffers of poison ${ }^{7}$. The idea is so simple: the separation of biodiversity (plants in this case) from the processes threatening them (herbivory) ${ }^{8}$.

Usually, positive outcomes of fencing plants are very fast, easy to evaluate and hence very intuitive. Fencing has a clear positive effect by avoiding herbivore grazing and trampling, also in some cases for human trampling and collection ${ }^{9,10}$. This usually results in an increasing of seed production and seedling survival at short term ${ }^{10-12}$. However, at medium or long term fencing produces important changes in vegetation composition and structure ${ }^{4}$. These drastic changes may have negative effects on a species such as: increasing intraspecific competition, limitation of seed dispersal for some zoochorous species ${ }^{13}$, and producing changes in population gene flow ${ }^{14}$. Also, it has indirect effects such as changes in pollination fauna and pollen dispersal due to these drastic changes in

${ }^{1}$ Department of Botany, University of Granada, 18071 Granada, Spain. ${ }^{2}$ Interuniversity Institute for Earth System Research, University of Granada, 18006 Granada, Spain. ${ }^{3}$ Department of Animal Biology, Plant Biology and Ecology, University of Jaén, 23071 Jaén, Spain. ${ }^{\circledR}$ email: jlorite@ugr.es 


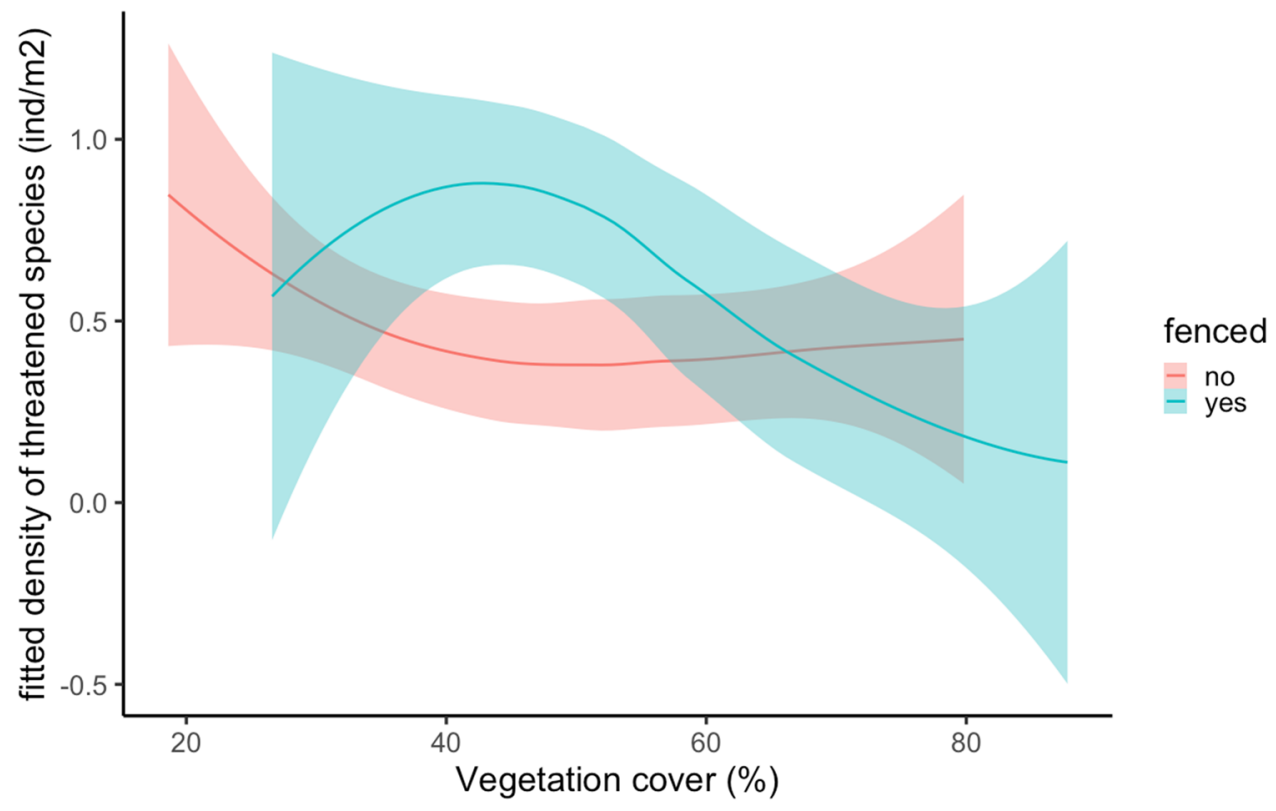

Figure 1. Relationship between vegetation cover (\%) and density (individual $/ \mathrm{m}^{2}$ ) of the focal threatened species for fenced (blue) and unfenced (red) habitat patches (fitted values adjusted by linear mixed model for all the species and populations, see Table S2).

the habitat ${ }^{14}$. Hence, many times the net outcome is difficult to foresee and even difficult to address. Moreover, fences produce aesthetic problems and management problems with stakeholders (e.g. farmers or hunters), or call effect for illegal collectors ${ }^{8}$. Altogether with high costs associated not only with installation, but also to their maintenance, that could not be affordable in most of extensive conservation programs ${ }^{15,16}$.

Although the pros and cons of fencing for conservation have largely assessed for animals, especially for large mammals (see ${ }^{8}$, for a review), the effects in plant conservation/protection against the herbivores are more scarce in literature.

Mediterranean ecosystems represent paradigmatic examples of this problem. They have been used for farmers since Neolithic and they constitute a hotspot of biodiversity with a large number of endemic species, many of them threatened by different factors mainly with anthropogenic origin. Among them, one of the most important threat factors is overgrazing ${ }^{17,18}$.

In this context, Sierra de Cazorla is an outstanding area within the Baetic-Rifan hotspot ${ }^{19}$. In this area there is a large number of herbivores both wild and domestic that produce overgrazing problems in some areas, especially in dry years. For this reason, since the middle 1980s some populations of threatened species were fenced ${ }^{20}$.

The results of pre-existing studies as well as our observations in this and other territories do not provide clear evidence regarding the suitability of this tool for managing threatened populations. Thus, it is crucial to assess these fenced populations in order to extract lessons for planning the installation of new fences, prioritizing the maintenance of the existing ones, or even the removal of the most detrimental for some endangered species.

We hypothesize that the effects of plant fencing as a tool to stop the threat of herbivory depends on both the site and the species. Thus, we aimed to assess fencing-induced changes at the individual, microhabitat and habitat levels in several populations of three threatened plant species.

\section{Results}

Unfenced areas presented an overall mean vegetation cover of $46.82 \pm 3.31 \%$ (ranging from 20 to $80 \%$ ), while for fenced areas cover was $54.69 \pm 3.06 \%$ (28-88\%). PERMANOVA showed significant differences in species composition based mainly in populations $(\mathrm{df}=4$; pseudo $\mathrm{F}=28.84 ; \mathrm{P}<0.001)$, but also in species $(\mathrm{df}=2$; pseudo $\mathrm{F}=1$. $.18 ; \mathrm{P}<0.001)$, and fencing/no fencing $(\mathrm{df}=1$; pseudo $\mathrm{F}=3.85 ; \mathrm{P}<0.005)$.

Relationship between focal species density and vegetation cover, regardless population and species, showed significant differences for fenced/unfenced populations (Tables S2, S3). At unfenced patches focal individuals tended to be more dense at lower cover values and remained with the same density along the cover gradient (Fig. 1). Meanwhile at fenced ones, intermediate values of vegetation cover presented a higher density for focal individuals, whereas at higher cover values (>60\%) density dropped sharply for fenced patches.

All the populations showed similar vegetative/reproductive ratios for fenced and unfenced patches (Figure S2), except for Solenanthus reverchonii where around 13\% of fenced individuals flowered and fructified, while unfenced ones behaved as vegetative in all cases. For the analysed traits, we obtained significant differences for fenced/unfenced populations in some cases, both among species and among populations within species. For vegetation cover (Fig. 2) we did not obtain significant differences between fenced and unfenced populations, except for one E. cazorlanum population (Puerto de Lezar; $\mathrm{P}=0.013$ ). Also, individual density of focal species 

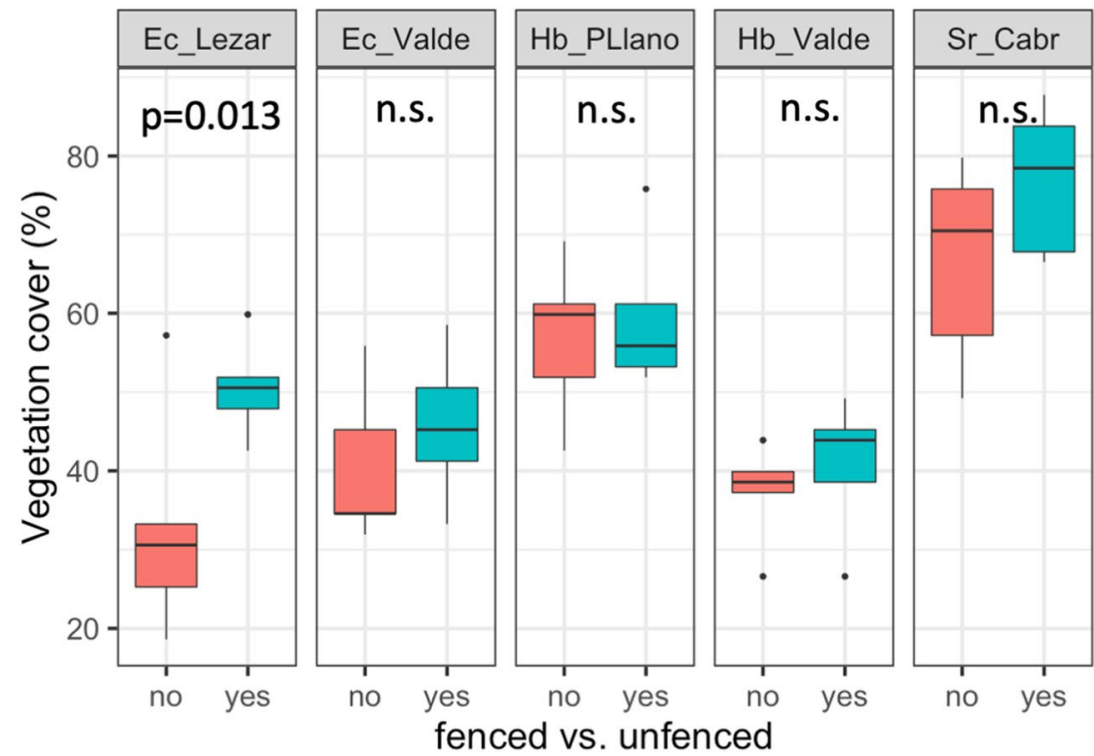

fenced

追 no

官 yes
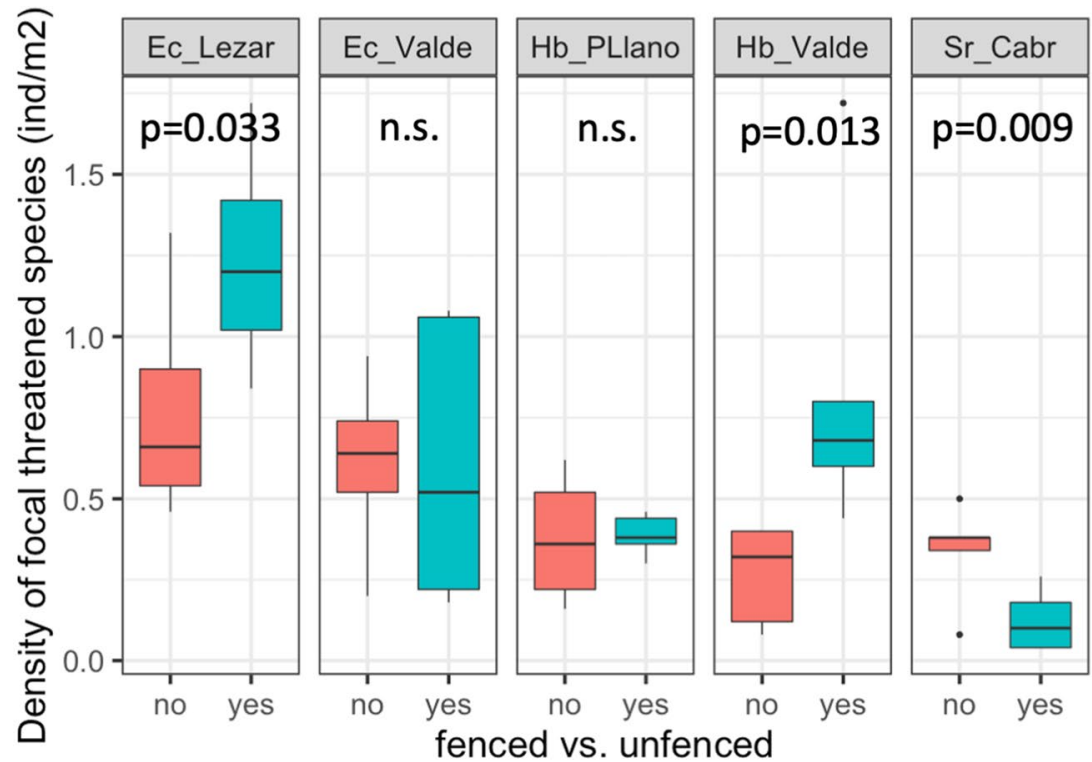

fenced

追 no

自 yes

Figure 2. Boxplot for cover (top graphs) and density (bottom graphs) of fenced and unfenced habitat patches for all the studied populations (see Table S1). P values indicated for each pair comparison were obtained after permutational ANOVA. Abbreviations for species and populations: Ec_Lezar Erodium cazorlanum-Puerto de Lezar, Ec_Valde Erodium cazorlanum-Valdeazores, Hb_PLlano Hormathophylla baetica-Puerto Llano, Hb_Valde Hormathophylla baetica-Valdeazores, Sr_Cabr Solenanthus reverchonii-Cabrilla Alta.

did not show a consistent pattern across populations (Fig. 2), while some populations presented a higher density in fenced patches other populations did not show significant differences. For Solenanthus reverchonii fenced population showed a lower density in comparison with unfenced areas $(\mathrm{P}=0.009)$.

When analysing biovolume as surrogate of plant biomass (Fig. 3) we did not obtain significant differences in fenced and unfenced patches, except for Solenanthus reverchonii, where fenced plants tend to be significantly bigger $(\mathrm{P}=0.000)$. In fact, no regeneration was found inside the fence and plants tend to be more scarce but bigger in size. Distance to the nearest neighbour (Fig. 3) increased in two populations, while sharply decreased in Solenanthus reverchonii $(\mathrm{P}=0.055)$.

Lastly, fruit production (Fig. 3) showed differences in just two populations (E. cazorlanum-Lezar, $\mathrm{P}=0.005$ and $H$. baetica-Valdeazores, $\mathrm{P}=0.009)$. Remarkably, in both cases unfenced populations produced significantly more fruits than fenced ones. 

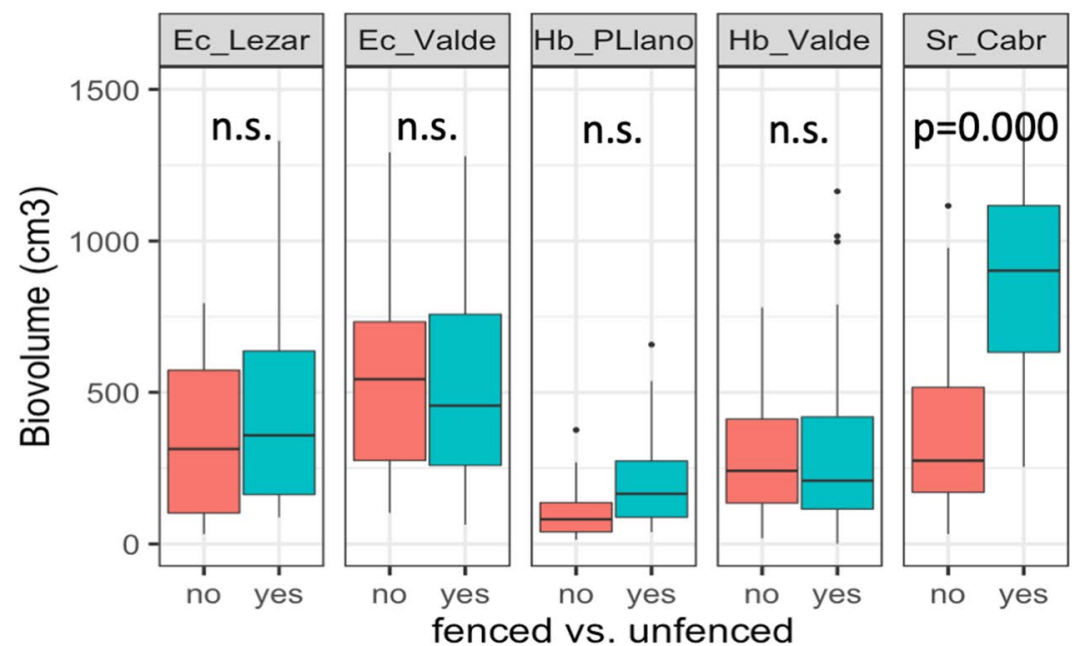

fenced

官 no
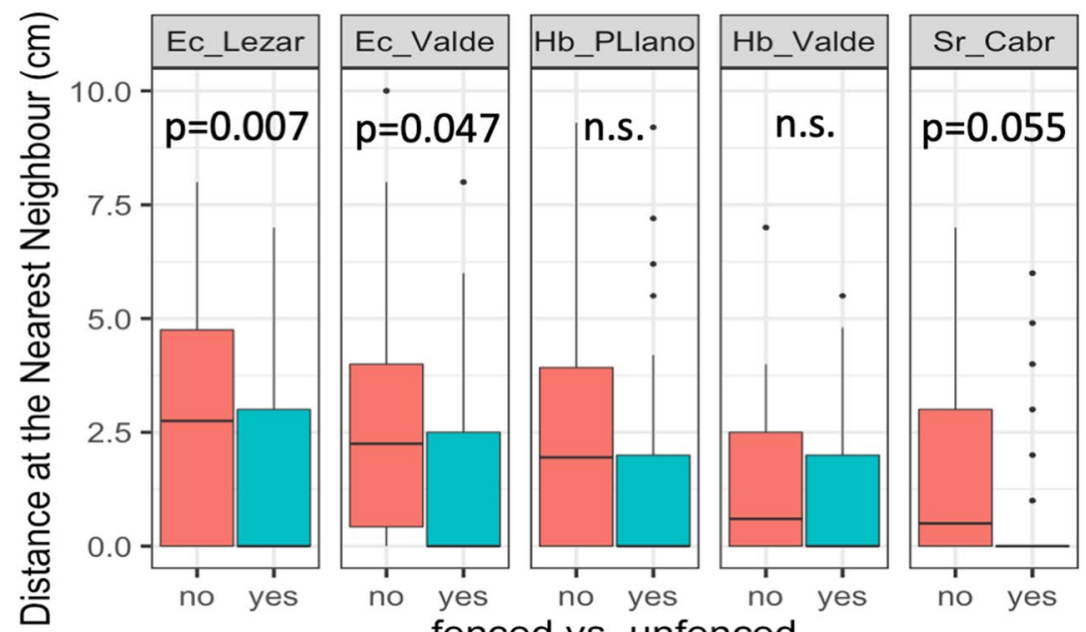

fenced

官 no
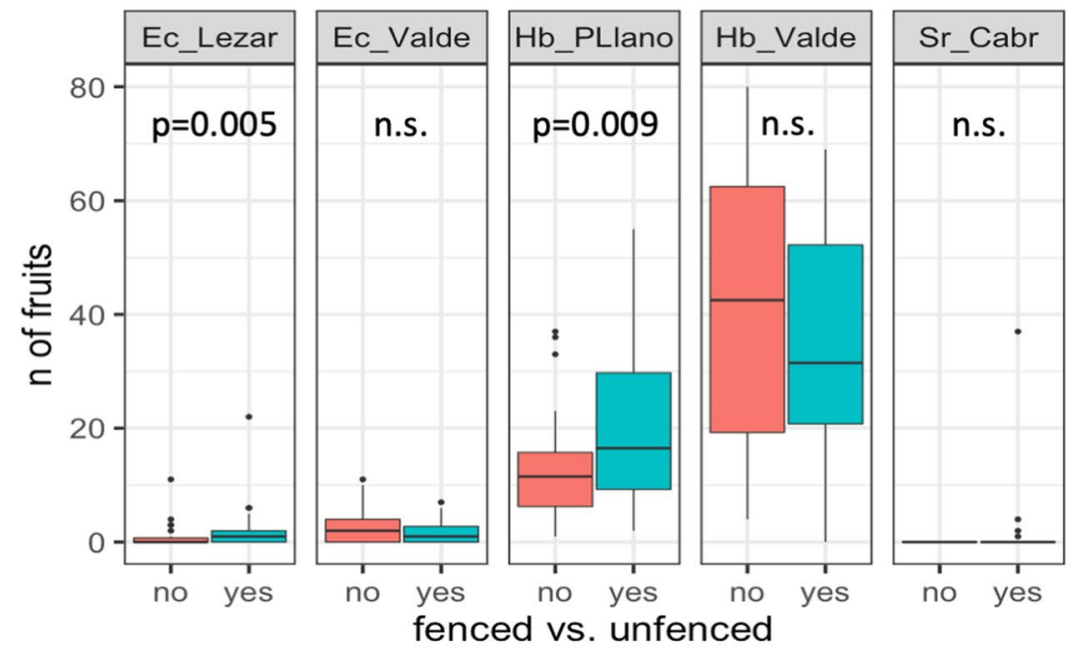

fenced

皇 no

Figure 3. Boxplot of biovolume (top graphs), distance to the nearest neighbour (centre graphs), and number fruit production (bottom graphs) for fenced and unfenced individuals ( $\mathrm{n}=30$ in all the cases) in all the studied populations (see Table S1). P values indicated for each pair comparison were obtained after permutational ANOVA. Abbreviations for species and populations: Ec_Lezar Erodium cazorlanum-Puerto de Lezar, Ec_Valde Erodium cazorlanum-Valdeazores, Hb_PLlano Hormathophylla baetica-Puerto Llano, Hb_Valde Hormathophylla baetica-Valdeazores, Sr_Cabr Solenanthus reverchonii-Cabrilla Alta. 


\section{Discussion}

As above stated, fencing is a commonly used tool in conservation biology $\mathrm{y}^{8,21}$. It is assumed that fencing has a positive effect over biodiversity, given that short-term response in plants is usually positive by avoiding herbivore grazing and trampling, human trampling, or collection ${ }^{9,11}$. Even though, this assumption is usually poorly supported by empirical data ${ }^{22}$. In fact to evaluate these long-term trends, even at short-term, is usually a neglected issue $^{21}$. In our study, for the three species analysed fencing has not always had positive consequences over the evaluated response variables at mid-term. In fact, we obtained contrasting results not only for species, but also for populations within a given species. Hence, medium or long-term effects of fences usually are related with complex both population and community dynamics ${ }^{23}$, being not so straightforward, and supporting the idea that net results in mid or long term is species- and habitat-dependent ${ }^{8}$. In some cases, moderate intensity trampling and grazing proved to be useful at medium term to limit the interspecific competition and undesirable changes in the vegetation structure for the target species ${ }^{10}$. Also, effect of grazing and trampling could greatly differ among species and populations within species, switching from positive to negative with complex interactions between them ${ }^{11,24}$.

One of the most influential factors in the net outcome of fencing is the change in vegetation cover in absence of herbivory, that may lead important changes in community structure and function ${ }^{23}$. In our study, the best performance for fenced populations was obtained at intermediate vegetation cover values, while for patches that become more densely vegetated after fencing, target species populations tend to significantly decrease, in line with other research results ${ }^{21}$. Herbivory alter vegetation cover and structure ${ }^{25}$. Hence, in absence of herbivory interspecific competition tend to increase significantly ${ }^{25,26}$, which may cause the negative consequences sometimes observed at mid or long term, especially for undercanopy species ${ }^{21}$, conducting to a homogenization of plant community ${ }^{23}$.

In general, altitude (as an arrange of different associated abiotic and biotic factors, ${ }^{27}$ ) is very influential in controlling an excessive increase in vegetation cover. In our cases, fenced high-mountain populations tended to perform better than in middle areas, as in high mountain areas environmental constrains limit cover and consequently the interspecific competence ${ }^{28}$. As a rule of thumb, we could establish that fences will exert better results for target species on naturally open habitats.

Habitat or microhabitat disparity in a given species may provoke differences in fencing performance ${ }^{13}$. For our target species, indicator variables (i.e. cover, density of focal species, biovolume, distance to the nearest neighbour, and fruit production) showed contrasting results for the populations within the same species and for the different indicator variables within the same population. Moreover, in most of the populations net outcome of the different features was not significantly different for fenced and unfenced species. This lack of a clear positive effect at mid-term over studied species do not justify the high costs associated with fencing installation and maintenance ${ }^{15,16}$. Together with potential conflict with stakeholders that may entail fencing ${ }^{8}$.

In some cases fencing could be even particularly detrimental for species ${ }^{14}$. We found a quite detrimental effect for Solenanthus reverchonii, with a declining tendency in fenced patch. This fact relies on the very low fruit production, no recruitment and an increased interspecific competence (high vegetation cover and virtually no distance with the nearest neighbour). Interestingly, this species is exozoochorous (i.e. Dispersal of seeds by being carried on the surface of an animal) $)^{18}$, thus the drastic change in habitat structure, sometimes becoming virtually impenetrable, may have restricted or even arrested seed dispersal ${ }^{13}$. Afterwards, seeds could not find suitable open sites typically inhabited by the species ${ }^{18,20}$. In this case fencing seemed to be positive at short term ${ }^{20}$, but over the years the population trend has become clearly negative.

The present study is focused in three species with different biotypes and contrasted habitats. However, the low number of species do not allow us to generalize our results. Also, to have detailed and quantitative information about the grazing pressure, would be very helpful. This lack of information for the area is clearly a limitation of the present work. Another important issue is the complete absence of the data at the starting point. Differences appearing prior to the fence installation may be influential even after 17-35 years. In this sense, to compile detailed information about the habitat and target species at the starting point is crucial to evaluate the midterm and long-term effects. Also, the presence of the fence could favour seed production and act as seed source dispersed to unfenced adjacent areas (i.e. for anemochorous or entomochorous seeds), thus minimizing the differences between fenced and unfenced areas. However, no apparent edge effect has been detected for habitat or target species variables. Despite these limitations, our study reveals that a previous evaluation (using the best available information), and a continuous monitoring is essential, not only at the short-term but also at midand long-term ${ }^{23}$. Also, for some species transformation of permanent fences in temporary ones could help to overcome partly the negative long-term effects of the total herbivory exclusion over community and population structure of the threatened species.

We have to rethink and re-evaluate all the existing fences, seeking for both ecological and economic viability. Furthermore, for establishing new fences an evaluation system must be implemented. In this regard, a plant functional type approach can be adopted ${ }^{29}$, compiling all the existing experiences, the scant literature, grey literature, and technical reports. Also, bearing in mind that fencing is only an emergency solution, and comprehensive measures, such as herbivore control (both wild and domestic) are always preferable despite controversial. Ultimately, grazing problem is just one of the consequences of the termed tragedy of the commons ${ }^{30}$.

\section{Methods}

Study area. The Sierra de Cazorla mountains s.l. are located in the northern part of the Baetic Mountain System (southeastern Spain, $38^{\circ} 05^{\prime} \mathrm{N} / 2^{\circ} 45^{\prime} \mathrm{W}$ ). Namely Cazorla, Segura, and Las Villas Natural Park, constitutes the largest protected area in Spain, covering 209,921 ha. The climatic regime is typically Mediterranean characterized by a hard summer drought. Average rainfall is about $1100 \mathrm{~mm}$ /year (ranging from 400 to 


\begin{tabular}{|l|l|l|l|}
\hline & Erodium cazorlanum & Hormathophylla baetica & Solenanthus reverchonii \\
\hline Family & Geraniaceae & Brassicaceae & Boraginaceae \\
\hline Biotype & Hemicryptophyte & Chamaephyte & Hemicryptophyte \\
\hline Flowering & Apr-May/Jul-Sep & Apr-May & Apr-May \\
\hline Pollination type & Biotic (insect) & Biotic (insect) & Biotic (insect) \\
\hline Fruiting & Jun/Sep-Oct & Jun & Jun-Jul \\
\hline Seed dispersal mode & Wind-dispersed and autochorous & Passive (barochorous) & Biotic (exozoochorous) \\
\hline Clonal reproduction & No & No & Stolons \\
\hline Distribution range & $\begin{array}{l}\text { Narrow endemic (Cazorla moun- } \\
\text { tains) }\end{array}$ & $\begin{array}{l}\text { Narrow endemic (Cazorla moun- } \\
\text { tains) }\end{array}$ & $\begin{array}{l}\text { Narrow endemic (Cazorla moun- } \\
\text { tains) }\end{array}$ \\
\hline Altitudinal range & $1500-2100$ m. asl & $1500-2000$ & $1700-1900$ \\
\hline Populations & 15 & 19 & 2 \\
\hline$n$ of individuals & 15,000 approx & 3500 approx & 340 \\
\hline Main threats & $\begin{array}{l}\text { Overgrazing (grazing and trampling) } \\
\text { Natural (restricted habitat) }\end{array}$ & $\begin{array}{l}\text { Overgrazing (grazing and trampling) } \\
\text { Natural (restricted habitat) }\end{array}$ & $\begin{array}{l}\text { Overgrazing (grazing and trampling) } \\
\text { Natural (restricted habitat) }\end{array}$ \\
\hline Threat category & Vulnerable (VU) & Vulnerable (VU) & Critically endangered (CR) \\
\hline
\end{tabular}

Table 1. Main features of the studied species ${ }^{18,20,38,44}$.

$1900 \mathrm{~mm}$ ), November and April being the wettest months, and July and August the driest ones, with marked interannual differences. Average temperature is $11.7^{\circ} \mathrm{C}$, with minimum in January $\left(4^{\circ} \mathrm{C}\right)$ and maximum in August $\left(21^{\circ} \mathrm{C}\right)$. Lithology consists mainly of limestone and dolomite ${ }^{31}$. A craggy topography characterizes these mountains, with altitudes ranging from 500 to $2107 \mathrm{~m}$ a.s.l. (Empanadas peak). The vegetation is composed of a mixture of pine forests (Pinus halepensis Mill., P. pinaster Ait. and P. nigra subsp. salzmannii (Dunal) Franco) with broad lived perennial or deciduous oaks such as: Quercus ilex L. and Q. faginea Lam. ${ }^{32}$. The total amount of the vascular plants accounted for the area are 2200, with 360 endemics to the Baetic-Rifan complex, 35 among them being narrow endemics to these mountains ${ }^{33}$. This mountain range has been overgrazed by domestic and wild ungulates at least during the last century $y^{34-36}$, affecting significantly the structure, composition and regeneration of the vegetation ${ }^{37}$. In fact, this is the main threat factor for endangered plant species in the area $^{38}$.

Studied species. We selected three endemic and threatened species (nomenclature as in ${ }^{39}$ ) Erodium cazorlanum Heywood, Hormathophylla baetica Küpfer, and Solenanthus reverchonii Degen. Species belong to important families in the area and their biotypes (i.e. Hemicriptophytes and chamaephytes) are dominant for threatened species (see Table 1). Also, all of them are threatened mainly by overgrazing and their populations have been partially fenced for 15-37 years (Table S1) with the so-called sheep fences or hog fences (see Figure S1) intended to avoid grazing by ungulates that mainly damage the populations of target species (see references above). This allows us to compare several habitat, microhabitat and target-species features (both habitat structure and reproductive) for fenced and unfenced patches blocking the rest of uncontrolled environmental variables. Using the information in the Regional Database for threatened flora ${ }^{40}$, we selected all the existing partially fenced populations with well-maintained fences, and having all of them about $50 \%$ of the individuals outside the fence., i.e. two populations for E. cazorlanum and H. baetica, and one for S. reverchonii (Table S1). Moreover, in absence of data at the starting point for crucial variables such for the community (i.e. grazing pressure, community composition) or individuals of target species (see variables below), this design allow us to compare between fenced and unfenced individual within the same population. The habitat for all the selected populations was an open pine woodland (Pinus nigra subsp. salzmannii) with short shrubs (frequently cushion-like shape shrubs ${ }^{41}$ ).

Sampling design. We performed the sampling from May to September 2016 (H. baetica and S. reverchonii) and May 2017 (for E. cazorlanum).

First, to evaluate the effect of fencing over the habitat we placed 10 transect of $25 \times 2 \mathrm{~m}\left(50 \mathrm{~m}^{2}\right), 5$ inside the fence and 5 outside the fence per species and population ( 50 transects in total). To assess the cover per species we used the intercept point method ${ }^{42}$ with 3-point contacts per meter (one in the centre and two in each side $1 \mathrm{~m}$ apart), 75 points per transect in total, so the cover per species was estimated as the percentage of point occupied by a given species. Also, density (individuals per square meter) of focal species (i.e. the three threatened species) was calculated by counting all the individuals in each $25 \times 2 \mathrm{~m}\left(50 \mathrm{~m}^{2}\right)$ band.

To assess the changes in the microhabitat of the threatened species (i.e. vicinity of each individual of the threatened species) we randomly selected 30 individuals inside the fence and 30 outside per population and species ( 60 individuals per populations $\times 5$ populations $=300$ individuals in total). For each individual, we placed a circular plot of $50 \mathrm{~cm}$ in diameter with focal individual in the central point. In each circular plot we recorded the frequency of all the perennial species, distance, and the identity of the nearest neighbour. Also, we recorded the fruit set of the focal individual, as well as its height and average diameter in order to calculate biovolume as the semispheroid formed ${ }^{43}$.

For identification and naming of the encountered species we followed Vascular Flora of Eastern Andalusia ${ }^{44}$. 
Data analysis. Statistical analyses were performed using $\mathrm{R}$ version $3.6 .1^{45}$.

We explored changes in species composition among populations both fenced and unfenced by means of multivariate analyses. First, we explored the influence of the categorical factors (i.e. species, population and fencing) over the matrix of species cover per transect by means of a permutational multivariate analysis of variance (PERMANOVA, Euclidean distance, with 999 permutations), by means of "adonis" function in R package vegan $2.5-2^{46}$. Relationship among cover and density for fenced vs unfenced patches for all the target species pooled was modelled by means of linear mixed models using "nlme" package ${ }^{47}$, including population and fence (fenced vs. unfenced) as fixed factors and transects nested in population as random factor. Model suitability was assessed by graphical exploration of the residuals ${ }^{48}$. To address differences in vegetation cover, density of each focal species, distance to the nearest neighbour, and fruit production, within each population for fenced and unfenced patches, we performed permutational ANOVAs by means of "lmPerm" package ${ }^{49}$, a flexible and very robust analysis that could cope with heteroscedasticity and a wide variety of statistical distributions. For graphs included we used ggplot 2 package ${ }^{50}$. Throughout the text means are expressed $\pm 1 \mathrm{SE}$.

Ethical approval. Authors declare that manuscript complies with all the institutional, national, and international guidelines and legislation, regarding all species and habitats studied.

Received: 16 April 2021; Accepted: 29 July 2021

Published online: 09 August 2021

\section{References}

1. Foley, J. A. et al. Global consequences of land use. Science 309, 570-574 (2005).

2. Chapin, F. S., Sala, O. E. \& Huber-Sannwald, E. Global Biodiversity in a Changing Environment Vol 152 (Springer, 2001 ).

3. Hobohm, C. Endemism in Vascular Plants (Springer, 2014). https://doi.org/10.1007/978-94-007-6913-7.

4. Al-Rowaily, S. L. et al. Effects of open grazing and livestock exclusion on floristic composition and diversity in natural ecosystem of Western Saudi Arabia. Saudi J. Biol. Sci. 22, 430-437 (2015).

5. Alonso, I., Hartley, S. E. \& Thurlow, M. Competition between heather and grasses on Scottish moorlands: Interacting effects of nutrient enrichment and grazing regime. J. Veg. Sci. 12, 249-260 (2001).

6. Diamond, J. Guns, Germs and Steel: The Fate of Human Societies (W.W. Norton \& Company, 1997). https://doi.org/10.4324/97819 12128273.

7. Hayward, M. W. \& Kerley, G. I. H. Fencing for conservation: Restriction of evolutionary potential or a riposte to threatening processes?. Biol. Conserv. 142, 1-13 (2009).

8. Hayward, M. W. et al. Fencing for conservation: Restriction of evolutionary potential or a riposte to threatening processes?. Biol. Conserv. 142, 1-13 (2009).

9. Santoro, R. et al. Effects of trampling limitation on coastal dune plant communities. Environ. Manag. 49, 534-542 (2012).

10. Fenu, G. et al. A common approach to the conservation of threatened island vascular plants: First results in the Mediterranean Basin. Diversity 12, 157 (2020)

11. Fenu, G., Cogoni, D. \& Bacchetta, G. The role of fencing in the success of threatened plant species translocation. Plant Ecol. 217, 207-217 (2016).

12. Fazan, L. et al. Free behind bars: Effects of browsing exclusion on the growth and regeneration of Zelkova abelicea. For. Ecol. Manag. 488, 118967 (2021).

13. Aschero, V. \& García, D. The fencing paradigm in woodland conservation: Consequences for recruitment of a semi-arid tree. Appl. Veg. Sci. 15, 307-317 (2012).

14. Bessega, C., Pometti, C., Campos, C., Saidman, B. O. \& Vilardi, J. C. Implications of mating system and pollen dispersal indices for management and conservation of the semi-arid species Prosopis flexuosa (Leguminosae). For. Ecol. Manag. 400, 218-227 (2017).

15. Scofield, R. P., Cullen, R. \& Wang, M. Are predator-proof fences the answer to New Zealand's terrestrial faunal biodiversity crisis?. N. Z. J. Ecol. 35, 312-317 (2011).

16. Tanentzap, A. J. \& Lloyd, K. M. Fencing in nature? Predator exclusion restores habitat for native fauna and leads biodiversity to spill over into the wider landscape. Biol. Conserv. 214, 119-126 (2017).

17. Valderrábano, E. M., Gil, T., Heywood, V. \& Montmollin, B. D. Conserving Wild Plants in the South and East Mediterranean Region (IUCN, International Union for Conservation of Nature, 2018). https://doi.org/10.2305/IUCN.CH.2018.21.en.

18. Bañares, A., Blanca, G., Guemes, J., Moreno, J. \& Ortiz, S. Atlas y Libro Rojo de la Flora Vascular Amenazada de España (Ministerio de Medio Ambiente Medio Rural y Marino, 2004).

19. Médail, F. \& Diadema, K. Glacial refugia influence plant diversity patterns in the Mediterranean Basin. J. Biogeogr. 36, 1333-1345 (2009).

20. Gutiérrez, L., García, S., Cuerda, D. \& Marchal, F. Aportaciones al conocimiento de la distribución y el estado de conservación del endemismo amenazado Solenanthus reverchonii Debeaux ex Degen (Boraginaceae ) en Andalucía ( España ). An. Biol. 36, 135-140 (2014).

21. Spooner, P., Lunt, I. \& Robinson, W. Is fencing enough? The short-term effects of stock exclusion in remnant grassy woodlands in southern NSW. Ecol. Manag. Restor. 3, 117-126 (2002).

22. Prober, S. M., Standish, R. J. \& Wiehl, G. After the fence: Vegetation and topsoil condition in grazed, fenced and benchmark eucalypt woodlands of fragmented agricultural landscapes. Aust. J. Bot. 59, 369-381 (2011).

23. Newman, M., Mitchell, F. J. G. \& Kelly, D. L. Exclusion of large herbivores: Long-term changes within the plant community. For. Ecol. Manag. 321, 136-144 (2014).

24. Cogoni, D., Fenu, G., Concas, E. \& Bacchetta, G. The effectiveness of plant conservation measures: The Dianthus morisianus reintroduction. Oryx 47, 203-206 (2013).

25. Schowalter, T. D. Herbivory. Insect Ecology 347-382 (Elsevier, 2006). https://doi.org/10.1016/B978-012088772-9/50038-8.

26. van der Waal, C. et al. Large herbivores may alter vegetation structure of semi-arid savannas through soil nutrient mediation. Oecologia 165, 1095-1107 (2011).

27. Körner, C. The use of 'altitude' in ecological research. Trends Ecol. Evol. 22, 569-574 (2007).

28. Körner, C. Alpine Treelines (Springer, 2012). https://doi.org/10.1007/978-3-0348-0396-0.

29. Anderson, P. M. L. \& Hoffman, M. T. Grazing response in the vegetation communities of the Kamiesberg, South Africa: Adopting a plant functional type approach. J. Arid Environ. 75, 255-264 (2011).

30. Hardin, G. The tragedy of the commons. Science (80-) 162, 1243-1248 (1968). 
31. Vera, J. A. Geología de Andalucía. Enseñanza Cien. Tierra 2, 306-317 (1994).

32. Gómez-Mercado, F. Vegetación y flora de la Sierra de Cazorla. Guineana 17, 1-481 (2011).

33. Benavente, A. Flora y vegetacion: Parque Natural de las Sierras de Cazorla, Segura y Las Villas. Anu. Adelantamiento Cazorla 50, 149-153 (2008).

34. Soriguer, R., Fandos, P., Granados, J., Castillo, A. \& Serrano, E. Herbivoría por ungulados silvestres en el piso mesomediterráneo de las Sierras de Cazorla, Segura y Las Villas. In "In memoriam" al profesor Dr Isidoro Ruiz Martínez 479-504 (Universidad de Jaén, 2003).

35. García-González, R. \& Cuartas, P. A comparison of the diets of the wild goat (Capra pyrenaica), Domesc Goat (Capra hircus), Mouflon (Ovis musimon) and the domestic sheep (Ovis aries) in the Cazorla Mountain range. Acta Biol. 9, 123-132 (1989).

36. Araque, E. Territorio y patrimonio rural en las sierras de Cazorla, Segura y las Villas. Nuevas perspectivas de investigación. Rev. PH 84, 28-47 (2013)

37. Tíscar Oliver, P. Patterns of shrub diversity and tree regeneration across topographic and stand-structural gradients in a Mediterranean forest. For. Syst. 24, 1-11 (2015).

38. Lorite, J., Navarro, F. B. \& Valle, F. Estimation of threatened orophytic flora and priority of its conservation in the Baetic range (S. Spain). Plant Biosyst. 141, 1-14 (2007).

39. Blanca, G. et al. Flora Vascular de Andalucía Oriental. vol. 4 (Servicios de Publicaciones de las universidades de Granada, Almería, Jaén y Málaga, 2011).

40. Mateos, M. et al. FAME. Aplicación Web de apoyo al seguimiento, localización e integración de la información sobre flora amenazada y de interés generada en Andalucía. In Tecnologías de la Información Geográfica: La Información Geográfica al servicio de los ciudadanos 222-229 (2010).

41. Valle, F. et al. Mapa de Series de Vegetación de Andalucía (Editorial Rueda, 2003).

42. Sutherland, W. J. Ecological Census Techniques: A Handbook 2nd edn. (Cambridge University Press, 2006).

43. Lorite, J., Peñas, J., Benito, B., Cañadas, E. \& Valle, F. Conservation status of the first known population of Polygala balansae in Europe. Ann. Bot. Fenn. 47, 45-50 (2010)

44. Blanca, G., Cabezudo, B., Cueto, M., Morales, C. \& Salazar, C. Flora vascular de Andalucía oriental (2a Edición Corregida y Aumentada) (Universidad de Granada, 2011).

45. R Core Development Team. R: A Language and Environment for Statistical Computing (R Core Development Team, 2019).

46. Oksanen, J. et al. vegan: Community Ecology Package. R package version 2.5-2. (2018).

47. Pinheiro, J. et al. nlme: Linear and Nonlinear Mixed Effects Models. (2020).

48. Zuur, A. F., Ieno, E. N., Walker, N., Saveliev, A. A. \& Smith, G. M. Mixed Effects Models and Extensions in Ecology with R Statistics for Biology and Health (Springer, 2009). https://doi.org/10.1007/978-0-387-87458-6.

49. Wheeler, R. E. R. et al. lmPerm: Permutation tests for linear models. 24 (2016)

50. Wickham, H. Elegant Graphics for Data Analysis (Springer, 2009).

\section{Acknowledgements}

We thank David Cuerda (Sierras de Cazorla, Segura y Las Villas Natural Park) and Sandra García de Lucas (Andalusian Network of Botanical and Mycological Gardens in Natural Areas) for their assistance at field work. We also thank the General Directorate of Environment (Junta de Andalucía) for allowing us access to FAME database. Project B1-RNM-163-UGR18-Programa Operativo FEDER 2018, partially financed this research.

\section{Author contributions}

J.L. conceived and design of this study. R.P. and J.L. collected the data. R.P. compiled the data. R.P. and J.L. constructed the database. J.L. analyzed the data and performed figures and tables. All authors wrote the manuscript, commented and improved it. All authors read and approved the final version of the manuscript.

\section{Competing interests}

The authors declare no competing interests.

\section{Additional information}

Supplementary Information The online version contains supplementary material available at https://doi.org/ 10.1038/s41598-021-95739-4.

Correspondence and requests for materials should be addressed to J.L.

Reprints and permissions information is available at www.nature.com/reprints.

Publisher's note Springer Nature remains neutral with regard to jurisdictional claims in published maps and institutional affiliations.

Open Access This article is licensed under a Creative Commons Attribution 4.0 International License, which permits use, sharing, adaptation, distribution and reproduction in any medium or format, as long as you give appropriate credit to the original author(s) and the source, provide a link to the Creative Commons licence, and indicate if changes were made. The images or other third party material in this article are included in the article's Creative Commons licence, unless indicated otherwise in a credit line to the material. If material is not included in the article's Creative Commons licence and your intended use is not permitted by statutory regulation or exceeds the permitted use, you will need to obtain permission directly from the copyright holder. To view a copy of this licence, visit http://creativecommons.org/licenses/by/4.0/.

(C) The Author(s) 2021 